\title{
Die Verklärung Jesu nach dem Markusevangelium
} Studien zu einer christologischen Legitimationserzählung

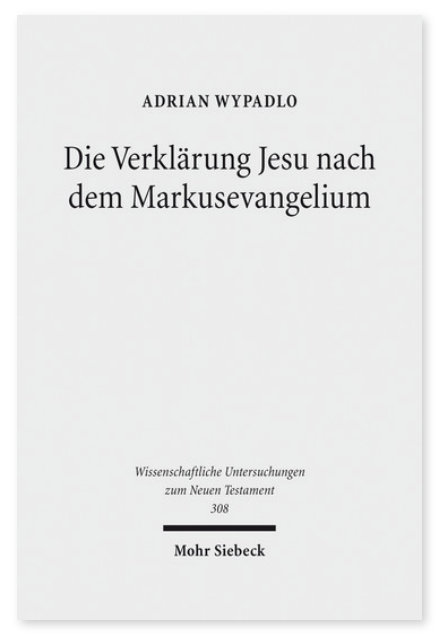

2013. XIII, 514 Seiten. WUNT I 308

ISBN 978-3-16-152561-2

DOI 10.1628/978-3-16-152561-2

eBook PDF 179,00€

ISBN 978-3-16-152560-5

Leinen $179,00 €$
Die Verklärungsperikope des Markusevangeliums (Mk 9,2-8) gilt als großes Rätsel der neutestamentlichen Wissenschaft. Tatsächlich stellt diese Erzählung den Ausleger in ihrer sonderbaren Mischung aus Faszination und Befremden vor große interpretatorische Herausforderungen. Welche Textgattung liegt hier vor und wie verhält es sich mit der historischen und der christologischen Wirklichkeit, die hinter dieser Narratio steht? Adrian Wypadlo bietet eine umfassende Interpretation der Transfigurationserzählung des Markusevangeliums mit der Grundthese, dass in Mk 9,2-8 zusammen mit der Taufperikope (Mk 1,9-11) die für den Makrotext zentrale christologische Legitimationserzählung vorliegt. Dabei unternimmt er den Versuch, eine alte These neu zu begründen: Der geistesgeschichtliche Nährboden, auf dem die Transfigurationserzählung wachsen konnte, ist die Exegese von Ex 24 und 34 im hellenistischen Judentum. Der Autor bietet nach einem umfassenden, der Vorverständigung dienenden Einleitungskapitel zunächst eine gründliche Einzelversanalyse des Textes, speziell unter narratologischen Aspekten. Dann vergleicht er diesen mit den Verwandlungsvorstellungen in der jüdisch-hellenistischen und paganen Umwelt des Neuen Testaments mit einem ständigen Seitenblick auf 2 Kor 3,18. Ein Schwerpunkt liegt auf Verwandlungsvorstellungen im Opus des jüdisch-hellenistischen Schriftauslegers Philo von Alexandrien. Besonderes Augenmerk legt der Verfasser hierbei auf dessen Exegese der entsprechenden Exodusstellen in VitMos und in Quaest in Ex /I. Abschließend fragt Wypadlo nach der auffälligen, aus Jesus, Elija und Mose bestehenden Figurenkonstellation in Mk 9,4f. Die Studie versteht sich somit als umfassenden Beitrag zur markinischen Christologie.

Adrian Wypadlo Geboren 1970; Studium der katholischen Theologie in Paderborn, Tübingen und Frankfurt; 1998 Priesterweihe; 2006 Promotion (Paderborn); 2011 Habilitation (Tübingen); seit 2012 Lehrstuhlvertreter am Seminar für Exegese des Neuen Testaments an der Kath.-Theol. Fakultät der Westfälischen-Wilhelms-Universität Münster; Dezember 2012 Ruf auf die Professur am Seminar für Exegese des Neuen Testaments an der Kath.-Theol. Fakultät der Westfälischen-WilhelmsUniversität Münster.

Jetzt bestellen:

https://mohrsiebeck.com/buch/die-verklaerung-jesu-nach-dem-markusevangelium-9783161525612?no_cache=1 order@mohrsiebeck.com

Telefon: +49 (0)7071-923-17

Telefax: +49 (0)7071-51104 